\title{
DO LEMBRETE AO POEMA: DE UM GÊNERO PRIMÁRIO PARA UM SECUNDÁRIO NUMA PERSPECTIVA BAKHTINIANA
}

\begin{abstract}
Sandra Aparecida da Silva Peixoto Mestranda em Linguística Aplicada pela Universidade de Taubaté (UNITAU) sandraaspeixoto@uol.com.br

Diogo Fernando dos Santos Mestrando em Linguística Aplicada pela Universidade de Taubaté (UNITAU) diogof.santos@globo.com

Luana Aparecida Galvão Mestranda em Linguística Aplicada pela Universidade de Taubaté (UNITAU) luanagalvao@uol.com.br
\end{abstract}

\section{RESUMO}

Bakhtin considera que a heterogeneidade dos gêneros decorre da relação entre a linguagem e as ações humanas, produzindo gêneros primários (simples) e secundários (complexos). Com isso, o objetivo deste estudo foi verificar a transposição de um gênero primário, o lembrete, para um secundário, o poema. Para tanto, a pesquisa fundamentou-se nas teorias bakhtinianas quanto ao estudo dos gêneros discursivos. Metodologicamente, procedeu-se a análise do corpus formado por um gênero primário, o lembrete, e um secundário, o poema Lembretes de Orides Fontela. Assim, os resultados mostraram que na transposição de um gênero para outro ocorre uma valoração do teor linguístico, que ganha maior elaboração, pois a complexidade dos gêneros secundários advém do fato de eles fazerem parte de um contexto em que a cultura letrada, e, por conseguinte, o discurso escrito, pertencem a uma estrutura mais complexa e organizada.

Palavras-chave: gêneros do discurso, gênero primário, gênero secundário, lembrete, poema.

\begin{abstract}
Bakhtin considers that the heterogeneity of the genres arises from the relation between language and human actions, producing primary (simple) and secondary (complex) genres. With this, the purpose of this study was to verify the transposition of a primary genre, the reminder, to a secondary, poem. For this, the research was based on the Bakhtinian theories regarding the study of the discursive genres. Methodologically, we proceeded to analyze the corpus formed by a primary genre, the reminder, and a secondary one, the poem Reminders of Orides Fontela. Thus, the results showed that in transposing from one genre to another, a valuation of the linguistic content, which acquires more elaboration, occurs because the complexity of the secondary genres arises from the fact that they are part of a context in which the literate culture, written discourse, belongs to a more complex and organized structure.
\end{abstract}

Keywords: discourse genres, primary genre, secondary genre, reminder, poem. 


\section{Introdução}

O interesse de Bakhtin pelos gêneros do discurso pautava-se mais no processo de formação do que nos aspectos formais. Para o autor russo (2016), a heterogeneidade dos gêneros existe porque há uma relação intrínseca entre o uso da linguagem e as atividades humanas. Além de que "os gêneros discursivos incluem toda sorte de diálogos cotidianos bem como enunciações da vida pública, institucional, artística, científica e filosófica" (MACHADO, 2014, p. 155).

Dessa forma, o objetivo deste artigo é verificar a transposição de um gênero primário, o lembrete, para um gênero secundário, o poema. Considerando que nesse decurso ocorre um processo de mutabilidade, quando uma forma mais simples se torna mais complexa, e, por conseguinte, ganha um caráter mais elaborado.

Concernente aos subsídios da fundamentação teórica, foram utilizadas as concepções de Bakhtin e do Círculo no que se refere ao estudo dos gêneros do discurso, bem como o aporte de Paz quanto à referenciação do gênero poema. No que tange à teoria bakhtiniana, procurou-se avaliar as concepções de gêneros primário e secundário e a inter-relação que se estabelece entre ambos; quanto a Paz, o seu uso amparou a observância do gênero poema.

Logo, este estudo contempla uma abordagem interpretativa em que se procedeu a análise de um corpus formado por um gênero do discurso primário, o lembrete Colocar carne no freezer, e um gênero do discurso secundário o poema Lembretes, de Orides Fontela. Para tal, consideraram-se, prospectivamente, os aportes teóricos já apresentados. 
Sendo assim, este artigo foi estruturado em três seções. Na primeira temos a fundamentação teórica quanto aos gêneros do discurso numa perspectiva bakhtiniana. Já na segunda, procedeu-se a constituição dos gêneros discursivos lembrete e poema à luz das ideias apresentadas por Bakhtin e o Círculo, bem como se fez o uso de Paz. Vale ressaltar, no entanto, que apesar de pertencerem a campos teóricos diferentes, verificaram-se pontos de contato entre ambas as teorias. Finalmente, na terceira seção, observou-se a transposição do lembrete - gênero primário - para o poema - gênero secundário.

\section{Os gêneros do discurso}

A vida completa diretamente a palavra, que não pode ser separada da vida sem que perca seu sentido.

Volóchinov

O homem é um ser de palavras. [...] A palavra é o próprio homem. Octavio Paz

Bakhtin (2016) propôs-se a estudar os gêneros considerando mais o seu processo de produção do que as suas propriedades formais. Interessava-lhe bem mais a correlação existente entre a utilização da linguagem e as atividades humanas, ambas constitutivas do dialogismo. De maneira que,

todos os diversos campos da atividade humana estão ligados ao uso da linguagem. [...] $\mathrm{O}$ emprego da língua efetua-se em forma de enunciados (orais e escritos) concretos e únicos, proferidos pelos integrantes desse ou daquele campo da atividade humana (BAKHTIN, 2016, p. 11). 
As análises bakhtinianas quanto ao gênero iniciaram-se na esfera literária, a partir do estudo do Romance, sua preocupação era não dissociar as várias esferas da vida humana do uso da linguagem, o homem é um ser histórico inserido num contexto. Conforme reitera Machado (2014), o interesse do autor russo pelo Romance deveu-se ao fato de que embora pertença à cultura letrada, representa a voz do homem que fala, que discute ideias e se posiciona no mundo. Não há como produzir um discurso no vazio; os enunciados não são e não podem ser produzidos fora da esfera do agir humano. A linguagem é a mobilidade constante do eu e do outro dentro das esferas históricas (VOLÓCHINOV, 2017).

Nessa perspectiva, Bakhtin (2016) observa que o gênero não pode ser considerado como estático ou imutável, pois não possui um modelo pronto, acabado e único, visto que a riqueza e diversidade dos gêneros do discurso são infinitas porque são inesgotáveis as possibilidades da multifacetada atividade humana e porque em cada campo dessa atividade vem sendo elaborado todo um repertório de gêneros do discurso, que cresce e se diferencia à medida que tal campo se desenvolve e ganha complexidade (BAKHTIN, 2016, p. 12).

Agimos por meio da interação, e nosso dizer se constrói a partir dos discursos proferidos, que, juntamente com a linguagem e as múltiplas esferas da vida do homem, fazem surgir tipos, de certo modo, estáveis de enunciados. Sendo assim, numa concepção bakhtiniana (2016), podemos afirmar que os gêneros são tipos de enunciados relativamente estáveis e caracterizados por apresentarem um conteúdo temático, uma construção composicional e um estilo.

O conteúdo temático, a construção composicional e o estilo são responsáveis por estabelecerem, de maneira geral, a constituição do enunciado, não esquecendo de se 
considerar, logicamente, a esfera de ação que irá determiná-lo. Ademais, essas características estabelecem uma interconexão entre a linguagem e a vida social, estando vinculadas ao domínio da atividade humana, o que confere certa maleabilidade aos gêneros, pois as atividades humanas são dinâmicas e mutáveis. Dessa forma, "a língua passa a integrar a vida por meio de enunciados concretos (que a realizam); é igualmente por meio de enunciados concretos que a vida entra na língua" (BAKHTIN, 2016, p. 16- 17).

Com isso, no que tange ao conteúdo temático, ele não se refere, especificamente, ao assunto do texto, mas sim ao domínio de sentido apresentado pelo gênero do discurso. Quanto à construção composicional, ela é o modo como o texto é estruturado. Sobre o estilo é válido dizer que ele é individual e, desse modo, torna-se reflexo da individualidade de quem fala ou escreve (BAKHTIN, 2016).

Desse modo, nenhum discurso pode ser compreendido fora do contexto no qual está inserido. Uma determinada palavra nunca deve ser considerada como uma ilha isolada em meio ao oceano. Na verdade, toda palavra é imbuída de um espírito significativo, que atrelada a uma conjuntura, faz com que o seu contexto fomente a necessidade de uma dialogia eficaz. Com isso,

a palavra é um evento social, não está centrada em sim mesma como certa magnitude linguística abstrata, nem pode ser psicologicamente deduzida da consciência do falante subjetiva e ilhada. É por isso que o enfoque linguístico formal e o psicológico disparam assim mesmo fora do neutro: a essência concreta e sociológica da palavra - a única que é capaz de convertê-la em verdade ou mentira, em vil ou nobre, em necessária ou em inútil - é vista segundo essas duas perspectivas como incompreensível e inacessível (VOLÓCHINOV, 2013, p. 85).

Sendo assim, todo processo de comunicação bem-sucedido depende de que seus interlocutores estejam em constante harmonia no que tange ao sentido daquilo que é 
proferido. Na percepção do Círculo bakhtiniano (2017), o que o locutor expressa não lhe pertence com exclusividade, os interlocutores celebram uma espécie de pacto do discurso no qual tudo o que é dito está intrinsicamente ligado. Desse modo, os diferentes gêneros textuais convivem entre si.

As articulações são dispostas de maneira que o discurso não seja em vão, pois ele deve encontrar um eco no outro, visto que "A palavra é o território comum entre o falante e o interlocutor" (VOLÓCHINOV, 2017, p. 205), portanto, não pode apresentar um discurso vazio. A palavra, também é história, é ideologia, é luta social, enfim, uma síntese das práticas discursivas historicamente construídas.

\subsection{Gênero primário e gênero secundário}

A diferença entre os gêneros primários (simples) e os secundários (complexos), é que os primeiros são os da vida cotidiana, predominantemente orais, e estão relacionados a uma comunicação verbal mais espontânea, além de possuírem uma ligação mais direta com o contexto no qual estão inseridos, como por exemplo, os diálogos do cotidiano, o lembrete, a carta. Já os segundos, surgem numa situação de comunicação mais elaborada, sendo, majoritariamente, escritos; apresentam-se em forma de romances, dramas, pesquisas científicas, entre outros (BAKHTIN, 2016).

Contudo, é válido ressaltar que Bakhtin (2016) não concebe os gêneros primário e secundário como sendo de realidades independentes. Para ele, ambos estabelecem uma relação de interdependência, o que corrobora para uma perspectiva não dicotômica, mas sim de inter-relação. Pois, 
no processo de sua formação eles incorporam e reelaboram diversos gêneros primários (simples), que se formaram nas condições da comunicação discursiva imediata. Esses gêneros primários, ao integrarem os complexos, nestes se transformam e adquirem um caráter especial: perdem o vínculo imediato com a realidade concreta e os enunciados reais alheios (BAKHTIN, 2016, p. 15).

Concomitantemente, é necessário observar que os gêneros discursivos são elos entre a linguagem e a história da sociedade. Todo e qualquer fenômeno, seja ele léxico, gramatical ou fonético, percorre um longo caminho histórico de elaboração e experimentação, para que, finalmente, possa integrar o sistema linguístico. A cada período, mudanças ocorrem, e elas também afetam a linguagem; assim, os gêneros transformam-se de acordo com as modificações na vida humana, não há, portanto, uma permanência, mas sim um diálogo constante, pois os gêneros primários e secundários misturam-se entre si. O verbal e o extra verbal fundem-se de maneira a estabelecer novas fronteiras para os gêneros do discurso e, com isso, abrir novas possibilidades.

Esse é o ponto de vista dos gêneros discursivos pensados numa escala comunicacional que se estende para além da interação verbal do dito e abarca o não dito da enunciação concreta sócio e culturalmente configurada. Essa é a dimensão prosaica no estágio contemporâneo da civilização (MACHADO, 2016, p. 165).

Assim, o tom valorativo é dado de acordo com determinado gênero do discurso, não necessariamente secundário, mas também primário. O tom é dado conforme a seleção de palavras feita pelo autor e a percepção dessa relação pelo ouvinte. Nesse encontro entre o autor e o ouvinte é que se constrói o valor que determinada palavra terá quando proferida ou não. Pois, segundo Volóchinov (2013), um poeta não retira de um dicionário as palavras que pretende utilizar, mas sim da vida cotidiana, quando elas 
estarão impregnadas de significância e inseridas num contexto. Na literatura, sobretudo, os valores subentendidos são importantes, já que "uma obra artística é um potente condensador de valorações sociais não expressadas: cada palavra está impregnada delas" (VOLÓCHINOV, 2013, p. 88).

Dessa forma, conclui-se que a significação, a palavra carregada de sentidos, é o que dá o tom valorativo, o qual perpassa pelas escolhas individuais que serão feitas. Não cabendo aqui uma imposição sistemática quanto ao que se deve ou não escolher. É importante prevalecer o diálogo e a sensibilidade, que permeará o constitutivo do gênero, visto que "A palavra é o esqueleto que se enche de carne viva somente no processo da percepção criativa e, por consequência, somente no processo da comunicação social viva." (VOLOCHÍNOV, 2013, p. 91). Os matizes da palavra são múltiplos e plurívocos, evocam sonhos, realidade, e, acima de tudo, evocam a vida.

\section{O lembrete e o poema}

Para a construção deste artigo optou-se por dois gêneros textuais distintos, o lembrete, gênero primário, e o poema, gênero secundário, cada qual com suas características e nuances próprias, além das implicações quanto ao uso da linguagem e o contexto em que estão inseridos.

Podemos fazer algumas considerações sobre o gênero lembrete. $O$ que exatamente o vocábulo lembrete evoca? Qual seria sua significação levando em conta aspectos como sua origem, sua história e sua função? De acordo com o dicionário Aurélio (2017), lembrete é uma anotação para lembrar coisas importantes. Essa definição da palavra remete à ideia do recordar. Todo lembrete, de certa forma, vem seguido de uma 
atitude, visto que a sua relevância reside, justamente, na realização de uma ação requerida por ele.

O gênero do discurso lembrete se caracteriza por ser um texto breve, claro e objetivo, possui caráter denotativo e está vinculado ao cotidiano, por isso o classificamos como pertencente ao gênero primário, haja vista a simplicidade quanto a sua constituição. Sua função está restrita à lembrança de algo e sua utilização faz parte de um contexto histórico e social. Considerando-se que

a peculiaridade das enunciações da vida cotidiana consiste em que elas, mediante milhares de fios, entrelaçam-se com o contexto extraverbal da vida e, ao serem separadas deste, perdem quase por completo seu sentido: quem desconhece seu contexto vital mais próximo não as entenderá (VOLÓCHINOV, 2013, p. 80).

Ainda no tocante ao gênero primário lembrete, é importante mencionarmos que, apesar de ser considerado como predominantemente oral, isso não se aplica a este aqui referido, o qual se apresenta de forma escrita. Ademais, ao escrevermos um lembrete, estamos numa esfera do cotidiano, portanto, não existe uma necessidade de grande elaboração linguística; o importante, nesse caso, é fazer-se entendido quanto ao lembrarse de algo.

Agora consideremos o gênero poema, pertencente ao mundo da literatura. Ele tem na palavra a sua matéria-prima primordial, a qual é lapidada de modo a constituir um significado que acentue a inter-relação entre o poeta e o leitor. Assim, "A língua do poeta é sua própria linguagem, ele está nela e é dela inseparável" (BAKHTIN, 1993, p. 94). Portanto, cabe dizer que a matriz linguística do poema é rica e variante, além de servir-se da linguagem como uma fonte inesgotável no talhe da construção poética. Ainda em 
conformidade com a criação poética, "Quaisquer que tenham sido as "tormentas verbais" que o poeta tenha sofrido no processo de criação, na obra criada, a linguagem passou a ser um órgão maleável, adequado até o fim ao projeto do autor" (BAKHTIN, 1993, p. 94).

Por sua vez, indo ao encontro do que afirma Bakhtin (1993), Paz diz que:

Somos feitos de palavras. Elas são a nossa única realidade ou, pelo menos, o único testemunho da nossa realidade. Não há pensamento sem linguagem, tampouco objeto de conhecimento: a primeira coisa que o homem faz com uma realidade desconhecida é nomeá-la, batizála (PAZ, 2014, p. 38).

O poema, nas palavras de Paz (2014), apresenta duas forças antagônicas, uma de desarraigamento, que irá arrancar a palavra da linguagem; e outra de gravidade, que a faz voltar. Dessa forma, a criação poética transmuta-se de maneira cíclica, exigindo que o poema se assente numa linguagem comum. Entretanto, é importante frisar que o comum aqui mencionado não se refere ao uso coloquial da língua, e sim ao pertencimento dela a uma comunidade.

A palavra [...] resolve a situação, ao proporcionar uma espécie de resumo valorativo. [...] uma enunciação da vida real continua ativamente e desenvolve uma situação determinada, assinala um plano para uma ação futura e a organiza. [...] atribuindo a essa comunidade material uma expressão ideológica e um desenvolvimento ideológico posterior (VOLÓCHINOV, 2013, p. 79).

De modo específico, a constituição do gênero poema relaciona-se a formas variadas, que podem ou não apresentar rima ou métrica. Ao longo da história, concebendo a literatura, tivemos desde formas fixas, como os sonetos, até formas consideradas mais livres, como os poemas modernos e os imagéticos. Contudo, o que não 
se pode negar é que a palavra é imprescindível, pois o "Poema é um organismo verbal que contém, suscita ou emite poesia" (PAZ, 2014, p. 22).

Ainda concernente ao gênero poema, ele pertence ao gênero secundário, de teor mais complexo, assim classificado por pertencer à esfera literária. As palavras assumem um caráter figurado, metafórico, ampliando, com isso, o significado. Além de que, segundo Bakhtin (2016), os gêneros secundários estão inseridos num contexto cultural mais complexo e desenvolvido, que pressupõe o predomínio da escrita.

\section{Do gênero primário para o gênero secundário: uma transposição de significados}

Para fins de observação, tomemos o seguinte lembrete: Colocar carne no freezer. Estamos diante de uma situação que requer, primeiramente, uma recordação importante de algo. Depois, de uma atitude que atenda ao apelo do que foi proferido. Diante desse contexto, vale ressaltar que o lembrete só terá êxito se a atitude de colocar a carne no freezer for realizada. A palavra lembrete está intimamente ligada ao vocábulo recordar do Latim recordari, e, segundo o dicionário Michaelis (2018) significa lembrar-se, trazer à memória o que se viveu. Assim, o gênero lembrete, ao longo da história, permitiu aos indivíduos terem em mente algo relevante para a vida prática. Além disso, nesse caso, o interlocutor a quem a mensagem se dirige, não fica evidente, podendo ser tanto um morador da casa, quanto o próprio enunciador, que, temeroso por esquecer-se de algo, estabelece um diálogo consigo mesmo.

Por outro lado, observemos que o poema Lembretes, de Orides Fontela, poeta cuja poesia pertence ao Modernismo brasileiro, marca-se pela reflexão filosófica, bem 
como apresenta, de acordo com Orione (2010), uma ênfase na objetividade e um apagamento da subjetividade, pois trata-se de uma poesia mais racional do que emotiva, de uma filiação não Romântica e, sim, Simbolista.

\author{
Lembretes \\ É importante acordar \\ a tempo. \\ É importante penetrar \\ o tempo. \\ É importante vigiar \\ o desabrochar do destino.
}

Aqui, temos a transposição de um gênero primário, o lembrete, para outro, de caráter secundário, o poema. Neste caso, o gênero poema adquire forma e força significativa no que diz respeito a lembrar-se de algo, característica que é própria do gênero lembrete. Deste modo, nesse processo de formação do gênero secundário a partir de um primário é válido lembrar que

eles incorporam e reelaboram diversos gêneros primários (simples), que se formaram nas condições da comunicação discursiva imediata. Esses gêneros primários, ao integrarem os complexos, nestes se transformam e adquirem um caráter especial: perdem o vínculo imediato com a realidade concreta e os enunciados reais alheios (BAKHTIN, 2016, p. 15).

Cabe então afirmar que o gênero do discurso lembrete, exemplificado em "Colocar carne no freezer" e já citado acima, é considerado um gênero primário, ou seja, de caráter simples e que o intuito é somente recordar. Por outro lado, o gênero poema, aqui presente com a obra Lembretes, de Orides Fontela, cuja forma composicional 
constitui-se de modo a remeter a um lembrete, é considerado um gênero secundário, ou seja, a plenitude do seu significado é complexa. Não é possível apreciá-lo desintegrado de um determinado contexto e tão pouco sem levar em conta o aspecto linguístico que ele exerce. Outrossim, é o fato de que o poema, conforme Orione (2010), é construído a partir de um gênero de caráter breve e utilitário, entretanto, nesse caso, a utilidade é substituída pelo aconselhamento meditativo.

Portanto, o que se conclui, é que essa substituição do utilitarismo pelo aconselhamento meditativo faz supor que o conteúdo temático residente no poema apresenta uma valoração de teor filosófico. Isso remete à ideia de que a partir de um conceito concreto apresentado por um lembrete, construiu-se a concepção abstrata vista no poema.

Uma vez que "As palavras ditas estão impregnadas do suposto e do não dito" (VOLÓCHINOV, 2013, p. 86). Paralelo a isso, é válido afirmar que o tema se fez do meditar filosófico implícito no dito e no não dito das palavras do poema. O engendramento temático deu-se no constitutivo de que o lembrar-se de algo, característica marcante do gênero lembrete, é substituído por um aconselhamento meditativo e não possui relação nenhuma com uma ação pontual a ser desenvolvida.

No que tange à forma composicional, o poema possui seis versos distribuídos em três estrofes, que, de acordo com Orione (2010), é recorrente na autora, pois sua construção poemática apresenta uma estrutura realizada de maneira contínua e similar, características que formarão um poema coerente e coeso; entretanto, por apresentarem certa independência quanto às partes, tornam-se cada vez mais densos e ambíguos. Escritos de forma bem sucinta, fazem rememorar um lembrete. Nesse sentido, o lembrete, aqui em questão, requer que a construção do entendimento vá além da sua 
simples aparência. Orides mantém a brevidade do gênero lembrete, contudo, subverte o seu conteúdo. Porquanto "a enunciação reflete em si a interação social entre o falante, o ouvinte e o herói, e vem a ser o produto e a fixação de sua interação viva no material da palavra" (VOLÓCHINOV, 2013, p. 87).

Logo na primeira estrofe o vocábulo acordar não se apresenta de modo a ser uma persuasão para quem dorme e precisa despertar de um sono. Na verdade, o que se pretende aqui é chamar a atenção, consoante Orione (2010), para o acordar para a vida. Na segunda estrofe, deparamo-nos com o uso do vocábulo penetrar. Essa palavra não pode ser tomada de maneira isolada, ou seja, sem considerar o seu emprego para o contexto em questão. Penetrar não pode ser compreendido como o ato de entrar. Assim, penetrar é uma tentativa de exortação. O lembrete requer uma atitude diante de nossa própria história (ORIONE, 2010). O eu-lírico espera uma tomada de decisão do seu interlocutor. Por fim, o mais enigmático é a expressão desabrochar, associada a destino, contida na terceira estrofe. Uma flor que se abre não cabe ao contexto. Porém, a imagem de uma flor que se abre remete ao interlocutor a necessidade de ser sentinela diante dos acontecimentos da vida. Conforme reitera Orione (2010), desabrochar e destino são condições para que nos posicionemos diante do futuro.

Em relação ao título Lembretes, ele transmite ao poema uma força de recordação. A necessidade de lembrar e agir diante da vida. A palavra, lembretes, retirada do seu uso habitual precisa ser entendida na perspectiva dialógica dos gêneros, uma vez que o discurso se realiza no plano do contexto. Ninguém é dono das palavras. De acordo com o círculo de Bakhtin (2017), o locutor tem direito sobre a palavra, mas o ouvinte também. Essa interação não significa apenas a troca de palavras isoladas, ela se constrói na experiência sócio-histórica que experimentamos ao longo da vida. 
Sobre o estilo, ao ampliar o seu sentido quanto ao que se esperava de um lembrete, Orides deixa claro o que deseja imprimir estilisticamente. Sua poesia, apesar de moderna, aproxima-se das odes gregas, todavia, nesse aspecto, considera o conteúdo. E nela observamos, segundo Orione (2010), uma poesia de conotação existencial e meditativa. Em Orides, o que temos é uma poética rica e concisa, que precisamente diz tudo com o pouco que apresenta. Conforme observa Volóchinov (2013), o estilo do poeta relaciona-se ao seu discurso interno, o qual não está sujeito a nenhum tipo de controle, e este discurso é produto de sua vida social.

Ademais, em literatura, os valores subentendidos são imprescindíveis, assim a força expressiva de uma palavra se faz tanto pelo que é dito, quanto por aquilo que não é dito. Visto que o

poeta não escolhe suas palavras de um dicionário, mas do contexto da vida no qual as palavras se sedimentam e se impregnam de valorações. [...] escolhe as valorações relacionadas com as palavras, e, além disso, desde o ponto de vista dos portadores encarnados destas valorações. Pode-se dizer que o poeta trabalha todo o tempo com a aprovação ou desaprovação, com a concordância ou a discordância do ouvinte (VOLÓCHINOV, 2013, p. 88).

De modo similar ao que observa Volóchinov (2013), Paz (2014) reitera que um poeta não escolhe as palavras que deseja usar, tampouco as procura em bibliotecas ou mercados. Ao encontrar a palavra desejada, percebe que já estava nela. "A palavra do poeta se confunde com o seu próprio ser. Ele é sua palavra" (PAZ, 2014, p. 53). Assim, ao estabelecer o estilo, cada um afirma o tom valorativo que anseia imprimir em sua obra.

Em suma, na transposição de um gênero primário, o lembrete, para um secundário, o poema, o que se percebe é que a riqueza vocabular se transmuta; o que 
outrora foi simples assume uma complexidade que nos desvela os mistérios que permeiam a palavra. Suas significâncias e amplitudes múltiplas são capazes de revelar um mundo a nossos olhos.

\section{Considerações finais}

Ao tratar dos gêneros do discurso, Bakhtin propôs-se a analisá-los numa perspectiva em que lhe interessava bem mais as implicações da enunciação do que os aspectos formais. Desse modo, verificou que há significativa heterogeneidade de gêneros discursivos, consoante a uma diferenciação entre gêneros primários e secundários.

Entretanto, os gêneros primário e secundário não são excludentes; ao contrário, existe um processo de dialogia entre ambos. Como reitera Bakhtin (2016), ocorre uma incorporação e reelaboração dos gêneros primários pelos secundários. Nesse âmbito, o que se observou foi que o gênero lembrete - primário - foi reconstituído a partir de um gênero secundário, o poema.

Nessa transposição de um gênero para outro, o poema de Orides Fontela, Lembretes, perscrutou um caminho em que o se lembrar de algo, como propõe o gênero lembrete, assumiu um novo significado. É válido considerar, com isso, que se partiu de um conceito denotativo, de posição clara e objetiva, colocar carne no freezer, para um prisma em que a construção linguística mais elaborada do poema dá outro tom, ou seja, o significado atrelado ao lembrar será considerado de maneira conotativa, metafórica. Assim, Orides manteve o conteúdo temático do lembrete, porém elaborou o poema de acordo com o que julgou importante lembrar. 
Quanto à constituição composicional, manteve a brevidade do gênero lembrete, já que o poema está disposto em três estrofes que apresentam dois versos concisos. Além de que, por se tratar de um gênero cuja esfera é a literatura, o estilo individual apresenta um fator de extrema importância, já que a escolha dos vocábulos evidencia propriedade estilística.

Em suma, ao elaborar o poema Lembretes, Orides Fontela fez com as palavras um grande labor estilístico, erigindo cada uma delas com o domínio de quem evoca a língua como algo constituinte da vida.

\section{Referências}

BAKHTIN, M. Os gêneros do discurso. Tradução do russo, organização, notas e posfácio de Paulo Bezerra, notas da ed. russa Serguei Botcharov. São Paulo: Editora 34, 2016.

Questões de literatura e de estética, a teoria do romance. 3. ed. Tradução Aurora Fornoni Bernardini, José Pereira Júnior, Augusto Góes Júnior, Helena Spryndis Nazário, Homero Freitas de Andrade. São Paulo: Editora Unesp, 1993.

LEMBRETE. Dicionário online Aurélio. Disponível em < $\underline{\text { https://dicionariodoaurelio.com>. }}$ Acesso em: 20 jul. 2017.

MACHADO, I. Gêneros discursivos. In: BRAIT, B. (org.). Bakhtin: conceitos-chave. São Paulo: Contexto, 2014, p. 151-166.

ORIONE, E. J. M. Filosofia e poesia em Orides Fontela. Revista FronteiraZ. São Paulo, n. 5, 2010, p. 176-183.

PAZ. O. O arco e a lira. 2. ed. São Paulo: Cosac Naify, 2014.

RECORDAR. Dicionário online Michaelis. Disponível em $<$ https://michaelis.uol.com.br/moderno-portugues/como-consultar/etimologia/>. Acesso em: 5 mar. 2018. 
VOLOCHINOV, V. N. A palavra na vida e a palavra na poesia, introdução ao problema da poética sociológica. In: VOLOCHÍNOV, V. N. A construção da enunciação e outros ensaios. Tradução João Wanderley Geraldi. São Carlos: Pedro \& João, 2013. p. 71-100.

Marxismo e filosofia da linguagem. Tradução, notas e glossário de Sheila Grillo e Ekaterina Vólkova Américo. São Paulo: Editora 34, 2017.

Recebido em 3 de agosto de 2018.

Aceite em 25 de setembro de 2018. 